\title{
Changes in Heart Rate Variability and Effects on POMS by Whether or Not Soil Observation Was Performed
}

\author{
Kazuyo Hanyu $^{1 * \#}$, Kenji Tamura ${ }^{1 \#}$, Hidetoshi Mori ${ }^{2}$ \\ ${ }^{1}$ Biosphere Resource Science and Technology Graduate School of Life and Environmental Science, University of Tsukuba, Tsukuba, \\ Japan; ${ }^{2}$ Division of Health Sciences, Graduate School of Technology and Science, Tsukuba University of Technology, Tsukuba, \\ Japan. \\ Email: "s1130258@u.tsukuba.ac.jp
}

Received December $2^{\text {nd }}, 2013$; revised January $2^{\text {nd }}, 2014$; accepted January $9^{\text {th }}, 2014$

Copyright (C) 2014 Kazuyo Hanyu et al. This is an open access article distributed under the Creative Commons Attribution License, which permits unrestricted use, distribution, and reproduction in any medium, provided the original work is properly cited. In accordance of the Creative Commons Attribution License all Copyrights (c) 2014 are reserved for SCIRP and the owner of the intellectual property Kazuyo Hanyu et al. All Copyright (C) 2014 are guarded by law and by SCIRP as a guardian.

\section{ABSTRACT}

Introduction: The effects of performing soil observation on autonomic nerve function (ANS) and the profile of mood states (POMS) particularly for upsurge of sentiment were studied table. Methods: The subjects were divided into two groups: Group A with soil observation, and Group B without it. Soil observation was performed by smelling soil, touching the soil and other ways. Evaluation was made using heart rate change variability, POMS and visual analog scale (VAS). Results: Group A showed an increase in high frequency (HF) and the LF (low frequency)/HF ratio and a decrease in heart rate, leading to activating the functions of the parasympathetic nervous system. VAS values for "not comforted at all" indicated that the scale was lower in Group A than in Group B. In POMS, a factor of “vigor” became lower in Group B than in Group A. Discussion: It was suggested that soil observation was effective in bringing people to a state of physiological and mental relaxation and reducing stress because it raised the degree of being comforted, increased HF, decreased the heart rate and activated the parasympathetic nervous system. Conclusions: By performing soil observation, the heart rate decreased, HF increased and an upsurge sentiment became normalized.

\section{KEYWORDS}

Soil Observation; Heart Rate Variability; Autonomic Nerve Function; Profile of Mood States (POMS); Visual Analog Scale (VAS)

\section{Introduction}

Psychotomatic impact of nature is researched frequently $[1,2]$. About the nature impact effect [3], the forest, the Satoyama [4], the river environment [5], the city environment [6] impact are researched in Japan. The IUFRO Conference on Forests for People is opened by IUFRO (International Union of Forest Research Organizations) in 2013, and the forest therapy is introduced as a new preventive medicine, and more and more nature effects to human are researched. The data about forest therapy are most, and some experts point out that a walk in the forest (forest therapy) is a feasible complementary alternative

\footnotetext{
*Corresponding author.

${ }^{\#}$ These authors contributed equally to this work.
}

therapy (CAM) and is effective when used in combination with other therapies [7]. Forest therapy, usually involving walk in the woods, was known to reduce stress and had a positive effect on the immune system [8]. The effect of forest therapy was considered, as a result of the compound collaboration of various environmental elements in the forest as they affected the five human senses [9]. And it is important to feel with our five senses of sight, touch and others. In 2004 and 2006, Ministry of Agriculture, Forestry and Fisheries of Japan made a study of the "Elucidation of the Effects of the Forest's Environmental Elements on Human Physiology" [10]. Miyazaki et al. [3] clarified that involvement with nature, such as forest therapy, brings a state of physiological and mental relaxation. Furthermore, there are papers report- 
ing the effect of natural environmental factors on people, namely, that the river environment reduced acute stress (healing effect) [5], the concentration of cortisol in saliva was lowered on the beach and in the Japanese black pine forest [4], and urban greenery environment reduced physiological and mental stress [6,11].

Nakamigi et al. [7] provided cancer patients with forest therapy, horticultural therapy, group therapy, yoga, and various CAM such as aromatherapy, acupuncture and moxibustion, and confirmed improvements in immune system and quality of life (QOL). Li [12] reported that forest therapy increased the number of human NK cells and the level of intracellular anti-cancer proteins.

On the other hand, Fukuda [13] conducted a questionnaire survey for 7 to 18-year-old Japanese people on the degree of their interest in nature's components (sunshine, air, soil and living things). Results of the survey revealed that their interest in soil was low compared with other components. Specifically, 68\% of the 7 to 12 -year-old respondents, $89 \%$ of the 13 to 15 year-old respondents and $97 \%$ of 16 to 18 year-old respondents had no interest in soil [13]. Also, Fukuda conducted a survey on Japanese second-grade senior high school students on whether they knew about and how much they understood various environmental issues, and the results indicate that they rarely knew that "soil is affected by humans," nor do they knew about "soil formation and its purification capacity and buffer capacity" or that "surface soil is important.”

Fukuda reports that the image of soil formed by children were greatly affected by whether they have been familiar with soil in their early childhood or what their parents' image of soil was (interest, understanding and knowledge). As a consequence, Fukuda suggested that it was necessary to educate children with programs to familiarize them with soil and create a model of practical thinking about soil.

As mentioned above, if the effect of soil observation through touching or seeing soil can improve human physiological functions and ease mental stress, it is possible to create a model of practical thinking about soil based on the obtained effect. In addition, integrative medicine using soil and greenery can be applied in clinical practice.

This study aims at clarifying the effect of soil observation on autonomic nerve system (ANS) function and the Profile of Mood States Brief Japanese Version (POMS) particularly for upsurge of sentiment.

\section{Methodology}

\subsection{Subjects}

The subjects were eleven male undergraduate and graduate students (age: $22.2 \pm 3.6$ years) who understood the purpose and details of the research after an explanation given orally and in writing and agreed in writing to become subjects. They were healthy without any specific diseases and did not take any medication and had no smoking habits. On the day previous to the experiment, they did not drink alcohol and went to bed by eleven o'clock at night. They finished a meal two hours before the commencement of the experiment.

By using the envelope method, they were divided into two groups. Group A was assigned to conduct soil observation and Group B was not assigned to this task. On a separate day, the subjects changed groups. The group of subjects first assigned to Group A were subsequently assigned to Group B on another day while the other group first assigned to Group B were then reassigned to Group A on another day. This research was implemented with prior approval from the research ethics committee of the University of Tsukuba.

\subsection{Measuring Procedures}

First, all the subjects took a10-min rest while in a sitting position, and then, by continuing to stay in a sitting position, Group A subjects performed "soil observation (5 min)" while Group B subjects performed "no soil observation (5 min)." Soil observation was performed on the green zone on the premises of Tsukuba University.

Measurement was conducted on clear days from eleven a.m. to three p.m. The average air temperature was $15.5^{\circ} \mathrm{C} \pm 2.4^{\circ} \mathrm{C}$, the average relative humidity was $47.9 \%$ $\pm 4.1 \%$ and the average atmospheric pressure was 1014.5 $\pm 2.0 \mathrm{hPa}$ with Group A while, with Group B, these values were $18.3^{\circ} \mathrm{C} \pm 2.4^{\circ} \mathrm{C}, 46.2 \% \pm 3.4 \%$, and $1012.2 \pm$ $1.6 \mathrm{hPa}$, respectively. There was no difference in significance between the two groups.

Electrocardiographic measurement (ECG) was performed on subjects for 10 minutes before the commencement of "soil observation" and "no soil observation" and for 10 minutes immediately after the end of "soil observation" and "no soil observation."

Blood pressure was measured at the end of the 10minute resting period (Pre), immediately after the performance (Post 0 ) and five minutes after the performance (Post 5) of "soil observation" and "no soil observation." Feelings of "being comforted/not comforted at all” and "not being stressed/being very stressed" were measured using VAS when "soil observation" or "no soil observation” was completed.

\subsection{Methodology of Soil Observation}

Soil observation was addressed to the litter layer (which is a layer of leaves, twigs that have fallen during certain times of year, deposited and semi-decomposed on the surface soil). Group A subjects looked at changes in fallen small twigs, smelled the soil, and touched the soil to 
understand its hardness and plasticity as in the previous study [14].

First "litter observation" was conducted by looking into the process of leaves and twigs decomposing into soil gradually from the litter surface while turning leaves over one by one to find the biological activity of small biological organisms and hyphae inside. Second, the action of "smelling soil" was done by putting the nose close to the soil on the palm of the subject's hand. Third "feeling the soil" was done by opening and closing the hand which was holding soil on its palm to feel soil temperature, soil wetness and consistency and determining field texture.

This study was done according to the description by the Japanese Society of Pedology (1997), In short soil hardness was measured by the thumb penetration resistance of soil, and soil plasticity was measured by the extended length of the aggregate of soil put on the palm of one hand with the addition of a small amount of water to give it sufficient wetness, then kneaded and shaped into a bar between the thumb and index finger.

The subjects of Group A put the soil mixed with fallen leaves on their palm, and then they put their noses to the soil to smell it. Next, they put soil on their palm and felt the texture of the soil by closing and opening the hand. In addition, they added a small amount of water to the soil and kneaded it between the thumb and the index finger to extend it into a bar shape. Soil observation was performed for a total of five minutes in a sitting position while neither doing bending/stretching exercises nor walking.

The subjects of the "no soil observation group" spent five minutes sitting on a simple folding chair (CAPTAIN STAG CS leisure chair M-3877, manufactured by Pearl Metal Co., Ltd., Japan) without soil observation.

\subsection{Assessment}

The data was obtained ECG signal measuring device (Memory heart rate monitor, LRR-03, GMS Co., Ltd., Japan) and loaded to the notebook computer (Dell Vostro1400, Japan) from the period before soil observation to 10 min after soil observation.

Frequency analysis on heart rate (HR) variation was performed using the analysis program MemCalc/Tonam2C (Suwa Trust, Japan). We determined low frequency (LF), high frequency (HF), LF/HF ratio, and HR was measured immediately before starting soil observation (Pre), for immediately after the soil observation was finished (Post 0), and for $5 \mathrm{~min}$ after $5 \mathrm{~min}$ from the soil observation was finished (Post 5). We calculated the values of sectional measurement of LF components of $0.04-0.15$.

We instructed the subjects before starting the soil ob- servation (experiment) to make each breath (expiration/ inspiration) last for 5 sec (12 times/min). Also, we directed them not to talk to each other, laugh, or cough (throat clearing) except when it could not be helped.

Blood pressure (systolic pressure, diastolic pressure) was measured at their left wrist joint region using a digital manometer (HEM-6200, OMRON, Japan) which uses an oscilloscope metric method.

Using VAS scores we measured their upsurge of sentiment on the items for "feeling comforted/not feeling comforted at all" and "not feeling stressed/feeling very stressed.” In VAS, a 100-mm horizontal line was drawn, starting from "feeling comforted" at the left end to "not feeling comforted at all" at the right end for the first item, and "not feeling stressed" at the left and "feeling very stressed" at the right end for the second item.

With POMS, we obtained normal scores of following six scales; tension—anxiety, depression, anger—hostility, vigor, fatigue, and confusion.

\subsection{Statistical Analysis}

Linear analysis was performed on both Groups A and B by two-way analysis of variance (ANOVA) and Fisher's PLSD multiple comparison on heart rate variation and blood pressure using a mixed model. Changes in each group were analyzed by ANOVA and Fisher's PLSD multiple comparison on heart rate variation and blood pressure using a mixed model. Student's t-test was performed on Groups A and B for a comparison of the two items of "feeling comforted/not feeling comforted at all" and "not feeling stressed/feeling very stressed," POMS "six scales," and air temperature/humidity/atmospheric pressure. The significance level was 5\%.

\section{Results}

\subsection{Changes of ANS}

The changes of ANS were shown Table 1. After soil observation, HF (msec2) increased at Post 5 (804.9 \pm 231.6) $(\mathrm{p}=0.028)$ compared with Pre (637.8 \pm 216.3$)$. LF/HF ratio had a decreasing tendency at Post 0 (3.8 \pm $0.8)(\mathrm{p}=0.195)$ and Post5 $(3.8 \pm 0.9)(\mathrm{p}=0.134)$ compared with Pre (5.1 \pm 1.7$)$. HR (beat $/ \mathrm{min})$ decreased at Post $0(68.7 \pm 2.1)(\mathrm{p}=0.001)$ and Post $5(69.9 \pm 2.1)(\mathrm{p}$ $=0.025)$ compared with Pre (71.4 \pm 2.3$)$.

There was no change in LF (msec2), and blood pressure $(\mathrm{mmHg})$.

\subsection{Comparison of Temporal Changes between Groups A and B}

There was no statistical difference between Groups A and $B$ in heart rate variability (LF, HF, LF/HF ratio), and blood pressure. 
Table 1. Heart rate variation and changes in blood pressure according to performing soil observation or not performing soil observation.

\begin{tabular}{lccc}
\hline & Pre & Post 0 & Post 5 \\
\hline Group A & & & \\
LF $\left(\mathrm{msec}^{2}\right.$ ) & $1746.7 \pm 366.8$ & $1599.5 \pm 243.4$ & $1725.8 \pm 327.3$ \\
HF $\left(\mathrm{msec}^{2}\right.$ ) & $637.8 \pm 216.3$ & $685.2 \pm 203.8$ & $804.9 \pm 231.6^{*}$ \\
LF/HF ratio & $5.1 \pm 1.7$ & $3.8 \pm 0.8$ & $3.8 \pm 0.9$ \\
HR (beat/min) & $71.4 \pm 2.3$ & $68.7 \pm 2.1^{* *}$ & $69.9 \pm 2.1^{*}$ \\
$\begin{array}{l}\text { Systolic pressure } \\
\text { (mmHg) }\end{array}$ & $110.7 \pm 4.0$ & $112.8 \pm 3.2$ & $113.3 \pm 4.0$ \\
$\begin{array}{l}\text { Diastolic pressure } \\
\text { (mmHg) }\end{array}$ & $70.1 \pm 4.3$ & $70.7 \pm 4.2$ & $70.5 \pm 4.1$ \\
$\begin{array}{l}\text { Group B } \\
\text { LF (msec }{ }^{2} \text { ) }\end{array}$ & $1126.3 \pm 199.6$ & $1374.9 \pm 237.3$ & $1326.5 \pm 236.5$ \\
$\begin{array}{l}\text { HF (msec }{ }^{2} \text { ) } \\
\text { LF/HF ratio }\end{array}$ & $342.3 \pm 139.1$ & $698.3 \pm 179.1$ & $713.9 \pm 185.1$ \\
$\begin{array}{l}\text { HR (beat/min) } \\
\begin{array}{l}\text { Systolic pressure } \\
\text { (mmHg) }\end{array}\end{array}$ & $71.4 \pm 3.1$ & $70.5 \pm 3.2$ & $70.9 \pm 3.1$ \\
$\begin{array}{l}\text { Diastolic pressure } \\
\text { (mmHg) }\end{array}$ & $71 \pm 4.3$ & $70.5 \pm 4.9$ & $73.7 \pm 5.1$ \\
\hline
\end{tabular}

Group A: soil observed, Group B: non soil observed; LF: Low Frequency, HF: High Frequency, HR: Heart Rate; ${ }^{*} \mathrm{p}<0.05,{ }^{* *} \mathrm{p}<0.01$; The values are mean \pm SE; For 5 min from the time immediately before starting soil observation (Pre), for 5 min from the time immediately after finishing soil observation (Post 0 ), and for $5 \mathrm{~min}$ after $5 \mathrm{~min}$ from finishing soil observation (Post 5).

\section{3. "Feeling Comforted/Not Feeling Comforted at All" and "Not Feeling Stressed/Feeling Very Stressed"}

Table 2 shows the VAS values for the items "feeling comforted/not feeling comforted at all" and "not feeling stressed/feeling very stressed." VAS indicated that those who observed soil (Group A) were more comforted ( $\mathrm{p}=$ 0.015). There was no difference between both groups for "not feeling stressed/feeling very stressed."

\subsection{POMS}

The changes in POMS in Groups A and B was indicated in Table 3. For "vigor," Group A showed no change and Group B decreased by 6 points.

\section{Discussion}

Complementary and alternative medicine (CAM) refers to a form of treatment to cure and bring benefits to patients that excludes Western medicine. For CAM, there are numerous reports on such fields as Chinese medicine, acupuncture, and aromatherapy with EBM [15-17]. It was said that expectations were high for "forest therapy," as one of the CAM therapies [18]. However, the positive
Table 2. Upsurge of sentiment according to performing soil observation or not performing soil observation (Degree of feeling comforted or feeling stressed).

\begin{tabular}{lcc}
\hline & Group A & Group B \\
\hline $\begin{array}{l}\text { Feeling comforted/not feeling } \\
\text { comforted at all }\end{array}$ & $24.9 \pm 5.2^{*}$ & $62.6 \pm 6.9$ \\
$\begin{array}{l}\text { Not feeling stressed/feeling very } \\
\text { stressed }\end{array}$ & $16.4 \pm 5.5$ & $33.3 \pm 10.5$ \\
\hline
\end{tabular}

Group A: soil observed, Group B: non soil observed; ${ }^{*} \mathrm{p}<0.05$; The values are mean $\pm \mathrm{SE}$.

Table 3. Normalized score of POMS according to performing soil observation or not performing soil observation (six scales).

\begin{tabular}{cccc}
\hline \multirow{2}{*}{ Tension-Anxiety } & Group A & $\begin{array}{c}\text { Before soil } \\
\text { observation }\end{array}$ & $\begin{array}{c}\text { After soil } \\
\text { observation }\end{array}$ \\
& Group B & $38.9 \pm 1.9$ & $38.7 \pm 1.7$ \\
Anger-Hostility & Group A & $42.3 \pm 1.0$ & $38.3 \pm 2.4$ \\
& Group B & $41.5 \pm 1.0$ & $41.8 \pm 1.2$ \\
Vigor & Group A & $38.3 \pm 0.8$ & $38.0 \pm 0.5$ \\
& Group A & $38.0 \pm 0.8$ & $38.3 \pm 1.0$ \\
Fatigue & Group B & $44.5 \pm 2.5$ & $48.0 \pm 2.9$ \\
& Group A & $41.4 \pm 3.2$ & $40.5 \pm 3.1^{*}$ \\
\multirow{2}{*}{ Confusion } & Group B & $39.4 \pm 1.6$ & $38.7 \pm 1.1$ \\
& Group A & $43.0 \pm 1.7$ & $41.5 \pm 1.6$ \\
& Group B & $43.6 \pm 2.2$ & $44.6 \pm 1.9$ \\
\hline
\end{tabular}

POMS: Profile of Mood States; Group A: soil observed, Group B: non soil observed; ${ }^{*} \mathrm{p}<0.05$; The values are mean $\pm \mathrm{SE}$.

effects of forest therapy were not especially evident ones [19].

Thus, it is desirable to take forest therapy concurrently with other therapies [19]. Soil observation is a part of forest therapy. This study suggested that soil observation activated the functions of the parasympathetic nervous system because of an increase in HF and a decrease in the ratio of LF with HF. Acupuncture stimulation caused a reduction in heart rates [20,21] as well as aromatherapy [22] and yoga [23].

The reduction in heart rate in this study may be prompted by soil observation in a way similar to acupuncture stimulation, aromatherapy, and yoga. In VAS, the subjects who performed soil observation had more of a sense of being "comforted," no changes in negative factors in POMS; the subjects who did not perform "soil observation" had decreased "vigor" compared with the subjects who performed "soil observation.” Improvement in POMS and mental factors by forest therapy has been reported [24].

The subjects who performed soil observation in this 
study were expected to be positively influenced mentally. The limit of this study is 0.502 (about 14 subjects) for $80 \%$ "effect size" of heart rate by Group A "with soil observation," which may be a sufficient number of subjects to withstand statistical analysis. The workload may not uniform among the three groups of "With soil observation," "Without soil observation (Control Group)," and "Intervention Group." For the future, we further need to examine data accumulation and influence on other factors, and if we are able to show the positive effect of "soil observation" on humans, this method will be able to contribute to the success of forest therapy.

\section{Conclusions}

The distinction between the people who under the soil observation performed or not is difficult, but the people by performing soil observation, the heart rate decreased, HF increased and an upsurge sentiment became normalized.

The subjects who performed soil observation showed a decrease in heart rate, increase in HF, and normalization in upsurge of sentiment.

\section{REFERENCES}

[1] N. M. Wells, "At Home with Nature: Effects of "Greenness” on Children's Cognitive Functioning,” Environment and Behavior, Vol. 32, No. 6, 2000, pp. 775-795. http://dx.doi.org/10.1177/00139160021972793

[2] A. Faber Taylor, F. E. Kuo and W. C. Sullivan, “Coping with ADD: The Surprising Connection to Green Play Settings,” Environment and Behavior, Vol. 33, No. 1, 2001, pp. 54-77. http://dx.doi.org/10.1177/00139160121972864

[3] Y. Miyazaki, J. Lee, B. J. Park, Y. Tsunetsugu and K. Matsunaga, "Preventive Medical Effects of Nature Therapy,” Environmental Health and Preventive Medicine, Vol. 66, 2011, pp. 651-656.

[4] T. Kasetani, K. Okumura, S. Yoshida, N. Takayama and T. Kagawa, "Differences in the Physiological and Psychological Effects of Walking in Various Satoyama Landscapes," Journal of the Japanese Institute of Landscape Architecture, Vol. 70, 2007, pp. 569-574. http://dx.doi.org/10.5632/jila.70.569

[5] Y. Tomita, K. Ito and K. Fujita, "Study on the Measurement of the Healing Benefits of River Environments by Salivary Cortisol and Salivary Amylase," Civil Society Annual Academic Lecture by Lecture Summary of 62nd. Japan Society Civil Engineers, Vol. 62, 2007, pp. 369370.

[6] M. Nasu, Y. Iwasaki and Y. Hayashi, "Physiological and Psychological Effects of Outdoor Green Space at an Urban Building Complex,” Shimizu Construction Research Reports, Vol. 88, 2011, pp. 19-26.

[7] M. Nakamigi and J. Imanishi, “A New Utilization of Urban Green Parks for Cancer Patients as a Therapeutic Space," Journal of the Japanese Society of Revegetation
Technology, Vol. 35, No. 2, 2009, pp. 301-303. http://dx.doi.org/10.7211/jisrt.35.301

[8] S. Homma, "Effect of Woodland Exposure on Humans, both Physical and Spiritual: A Medical Investigation," Journal of Aroma Science and Technology, Vol. 6, 2005, pp. 47-53.

[9] N. Takayama, T. Kagawa, T. Kasetani, B. J. Park, Y. Tsunetsugu and Y. Oishi, "The Comfortableness of Light/ Thermal Environment for Bathing in the Forest Atmosphere,” Journal of the Japanese Institute of Landscape Architecture, Vol. 68, No. 5, 2005, pp. 819-824. http://dx.doi.org/10.5632/jila.68.819

[10] Y. Tsunetsugu, B. J. Park, J. Lee, T. Kagawa and Y. Miyazaki, "Psychological Relaxation Effect of Forest Therapy: Results of Field Experiments in 19 Forests in Japan Involving 228 Participants,” Japanese Journal of Hygiene, Vol. 66, No. 4, 2011, pp. 670-676. http://dx.doi.org/10.1265/jih.66.670

[11] Y. Iwasaki, “Green Design for Human Health,” The Japanese Society of Revegetation Technology, Vol. 36, No. 2, 2010, pp.243-244. http://dx.doi.org/10.7211/jjsrt.36.243

[12] Q. Li, "Effect of Forest Bathing Trip on Human Health," Anti-Aging Medicine, Vol. 5, 2009, pp. 362-367.

[13] T. Fukuda, "Situation and Subjects of Soil Education in Elementary and Secondary School," Pedologist, Vol. 48, 2004, pp. 109-116.

[14] M. Asano, “Let's Turn over the Leaves: New Edition "How to Teach that the Soil Is Useful Environmental Education Material in the Field," Committee of Soil Education, Japanese Society of Soil Science and Plant Nutrition, 2009, p. 18.

[15] H. Satoh, "Kampo Pharmacology: Kampo Medicines as Complementary and Alternative Medicine (CAM)," Folia Pharmacologica Japonica, Vol. 140, No. 2, 2012, pp. 5457. http://dx.doi.org/10.1254/fpj.140.54

[16] T. Yano, "Toward the Internationalization of Acupuncture and Integrative Medicine,” The Bulletin of Meiji University of Integrative Medicine, Vol. 1, 2009, pp. 7-12.

[17] J. Imanishi, "Green Environment and Integrative Medicine," The Japanese Society of Revegetation Technology, Vol. 33, No. 3, 2008, pp. 435-440. http://dx.doi.org/10.7211/jjsrt.33.435

[18] J. Imanishi, M. Nakamigi, A. Imanishi, J. Imanishi, E. Watanabe, M. Kimura and Y. Morimoto, "Effect of a Health Promotion Program Consisting of Forest Therapy, Horticultural Therapy and Yoga on Healthy Elderly,” The Japanese Society of Revegetation Technology, Vol. 35, No. 2, 2009, pp. 363-369. http://dx.doi.org/10.7211/jjsrt.35.363

[19] J. Imanishi, "Medical Aromatherapy,” Japanese Journal of Complementary and Alternative Medicine, Vol. 1, No. 1, 2004, pp. 53-61. http://dx.doi.org/10.1625/jcam.1.53

[20] K. Nishijo, H. Mori, K. Yoshikawa and K. Yazawa, "Decreased Heart Rate by Acupuncture Stimulation in $\mathrm{Hu}-$ mans via Facilitation of Cardiac Vagal Activity and Suppression of Cardiac Sympathetic Nerve,” Neuroscience Letters, Vol. 227, No. 3, 1997, pp. 165-168. http://dx.doi.org/10.1016/S0304-3940(97)00337-6

[21] H. Mori, K. Nishijo, H. Kawamura and T. Abo, "Unique 
Immunomodulation by Electro-Acupuncture in Humans Possibly via Stimulation of the Autonomic Nervous System,” Neuroscience Letters, Vol. 320, No. 1-2, 2002, pp. 21-24. http://dx.doi.org/10.1016/S0304-3940(02)00012-5

[22] J. Buckle, “Aromatherapy,” Nursing Times, Vol. 89, 1993, pp. 32-35.

[23] E. Oguchi and H. Kasai, "The Effect of Stretch Exercise with Deep Breath on Autonomic Nervous System in Standing Position: Assessment by the Frequency Domain Analysis of Heart Rate Variability,” The Journal of Tokyo Academy of Health Science, Vol. 1, 1999, pp. 85-88.

[24] T. Kasetani, "Psychological Relaxation Effects of Forest Therapy," Research Journal of Food and Agriculture, Vol. 30, No. 7, 2007, pp. 20-23. 